\title{
Salvianolic acid B activates Wnt/ $\beta$-catenin signaling following spinal cord injury
}

\author{
HONGMING ZHOU ${ }^{1}$, YI LIU ${ }^{2}$, LEI SUN ${ }^{3}$, MING FU $^{4}$ and YAO ZHAO ${ }^{5}$ \\ Departments of ${ }^{1}$ Emergency Trauma Surgery and ${ }^{2}$ Bone Surgery, Linyi City Central Hospital, Linyi, Shandong 276400; \\ ${ }^{3}$ Department of Orthopedics, Taian City Central Hospital, Taian, Shandong 271000; ${ }^{4}$ Department of Bone Surgery, \\ Heilongjiang Provincial Hospital, Harbin, Heilongjiang 150000; ${ }^{5}$ Department of Spine Surgery, Provincial Ear, \\ Nose and Throat Hospital, Shandong Provincial Ear, Nose and Throat Hospital \\ Affiliated to Shandong University, Jinan, Shandong 250012, P.R. China
}

Received December 18, 2018; Accepted August 16, 2019

DOI: $10.3892 /$ etm.2019.8292

\begin{abstract}
Neural cell apoptosis serves a key role in spinal cord injury (SCI), which is a threat to human health. The present study aimed to evaluate the neuroprotective mechanism of salvianolic acid B (Sal B) in a spinal cord injury (SCI) rat model. Basso, Beattie, and Bresnahan scores demonstrated that Sal B treatment significantly increased locomotor functional recovery in SCI rats compared with SCI model rats between 3 and 8 weeks. Nissl staining demonstrated that Sal B enhanced motor neuron survival and decreased lesion size after SCI. Reverse transcription-quantitative PCR analysis demonstrated that Sal B treatment significantly enhanced the mRNA levels of lymphoid enhancer biding factor-1 and HNF1 homeobox A. In addition, Sal B treatment enhanced the expression of $\beta$-catenin. Western blot analysis determined that Sal B treatment significantly decreased the expression of pro-apoptosis proteins, including Bax, cleaved caspase- 3 and -9 , in spinal cord tissues after SCI but enhanced the expression of Bcl-2, an anti-apoptotic protein. Furthermore, terminal deoxynucleotidyl transferase dUTP nick end labeling (TUNEL) staining demonstrated that, compared with the SCI group, Sal B treatment decreased the number of TUNEL-positive neurons. In summary, the present study produced novel data demonstrating the neuroprotective effect of Sal B on SCI with the mechanism likely primarily mediated via the $\mathrm{Wnt} / \beta$-catenin signaling pathway. The present findings may be of potential therapeutic value for future SCI treatments.
\end{abstract}

Correspondence to: Dr Yao Zhao, Department of Spine Surgery, Provincial Ear, Nose and Throat Hospital, Shandong Provincial Ear, Nose and Throat Hospital Affiliated to Shandong University, 4 Duanxing Xi Road, Jinan, Shandong 250012, P.R. China E-mail: yaozhaoguke@163.com

Key words: salvianolic acid B, spinal cord injury, Wnt/ $\beta$-catenin signaling, apoptosis

\section{Introduction}

Neural cell apoptosis has a key role in secondary injury, which directly affects the recovery of white matter and neurological function (1) during spinal cord injury (SCI). Apoptosis is a major regulator of the process of secondary injury (2). Hence, the suppression of apoptosis can prevent or decrease secondary injury, thereby improving nerve function and preventing nerve cell loss $(3,4)$. Although great advances have been made in the field of SCI, effective therapy methods are still lacking.

The Wnt family are a class of glycoproteins that are widely involved in neural development, axonal guidance, cell proliferation and neural cell survival $(5,6)$. In acute respiratory distress syndrome and colorectal cancer, Wnt/ $\beta$-catenin signaling has been shown to be involved in the regulation of cell apoptosis $(7,8)$. It has been reported that $\mathrm{Wnt} / \beta$-catenin signaling, which enhances the functional recovery of the injured spinal cord, is activated following SCI (9).

Salvianolic acid B (Sal B), an active pharmaceutical compound isolated from Salvia miltiorrhiza, has been shown to be neuroprotective in animal models of brain injury and SCI $(10,11)$. Previous studies have demonstrated that Sal B can promote the recovery of neurological function $(12,13)$. However, whether these beneficial effects of Sal B are correlated with Wnt/ $\beta$-catenin signaling has not been elucidated.

The present study aims to evaluate the neuroprotective mechanism of Sal B in SCI rats, which may be of potential therapeutic value for future SCI treatment.

\section{Materials and methods}

Animals and Sal B treatment. The present study was approved by the Animal Ethics Committee of Shandong Provincial Hospital Affiliated with Shandong University. A total of 18 adult male Sprague Dawley rats (weight range, 220-250 g; age, 6-8 weeks) were purchased from Shanghai Laboratory Animal Center, Chinese Academy of Sciences (Shanghai, China). The rats were maintained in the animal experimental center of Shandong University with four animals housed per cage under a 12-h light/dark cycle. Room temperature was maintained at 
$23 \pm 1^{\circ} \mathrm{C}$, the humidity was maintained at $\sim 60 \%$, and all rats had free access to food and water.

The rats were randomly divided into three groups ( $n=6$ for each group): The sham group, the SCI group and the Sal B+SCI group. Sal B (cat. no. M5250; Sigma-Aldrich; Merck KGaA) stock solutions $(0.5 \mathrm{mg} / \mathrm{ml})$ were prepared in $0.1 \mathrm{~mol} / 1 \mathrm{NaOH}$ and diluted 1:10 in $0.1 \mathrm{~mol} / 1$ phosphate-buffered saline (PBS) prior to use with the $\mathrm{pH}$ of the solution adjusted to 7.4-7.6. For the sham group, rats received no other treatments. For the SCI group, the rats received $0.1 \mathrm{~mol} / 1 \mathrm{PBS}$ instead of Sal B.

Before the study, three Sal B dose groups were chosen: $2 \mathrm{mg} / \mathrm{kg}$ (low dose group), $10 \mathrm{mg} / \mathrm{kg}$ (medium dose group) and $20 \mathrm{mg} / \mathrm{kg}$ (high dose group). Preliminary experimental results showed that there were differences in cell viability between Sal B high dose group (20 mg/kg group) and the other groups from the 7th day following SCI, with the effect of Sal B on reducing SCI positively correlated with the concentration (data not shown). A previous study also indicated that $20 \mathrm{mg} / \mathrm{kg}$ Sal B was optimal for postoperative neurological functional recovery (12). Combined with our data and the previous report, the dose of Sal B $20 \mathrm{mg} / \mathrm{kg}$ was selected for subsequent experimentation. For the Sal B+SCI group, the Sal B group rats were treated with $20 \mathrm{mg} / \mathrm{kg}$ Sal B 24-h following SCI. A total of 8 rats were in the sham group, 8 rats were in the SCI group and 8 rats were in the Sal B+SCI group.

Establishment of SCI rat model. The rat model of SCI was established as previously described (14). The rats in the sham surgery group underwent all aspects of the surgery except for thoracic contusion injury. Following $8 \mathrm{~h}$ of fasting, the rats were anesthetized with $10 \%$ chloral hydrate $(400 \mathrm{mg} / \mathrm{kg})$ (Vigorous Biotechnology Beijing Co., Ltd.) via intraperitoneal injection in accordance with a previous study (15). No signs of peritonitis were observed in any of the animals following administering chloral hydrate.

Subsequently, the rats were placed in a prone position and an incision $(\sim 2.5 \mathrm{~cm}$ in length) was made in the middle of the back. The skin was cut layer by layer and the T8 to T10 vertebral plates were exposed. Total laminectomy of the T9 vertebral plate was performed to expose the spinal dura mater. The T8 and T10 spinous processes were fixed using forceps. A Kirschner wire $(10 \mathrm{~g})$ was inserted into the aorta via a catheter with a weight that fell freely from a $25-\mathrm{mm}$ height. Following this, a semicircular slice $(4 \times 2 \mathrm{~mm})$ made from thin plastic was used to impact the spinal cord and the wire was immediately removed, resulting in incomplete injury of the rat spinal cord. The incision was sutured layer by layer. Following the injury, tail-wagging reflex, retraction flutter of the lower limbs and body, and the flaccid paralysis of the lower limbs during the awake state indicated the successful establishment of a model of SCI (Fig. 1) (14).

The rats in the treatment group were intraperitoneally administered with $20 \mathrm{mg} / \mathrm{kg}$ Sal B dissolved in $1 \mathrm{ml}$ of PBS, once a day, for eight consecutive weeks based on the results of a previous study and our preliminary experiments performed in the Shandong Provincial Hospital Affiliated with Shandong University (Shandong, China) (12). No changes in locomotion or mental state were observed in the rats from the SCI, $\mathrm{SCI}+\mathrm{Sal} \mathrm{B}$-treated or sham groups in the present study therefore, $20 \mathrm{mg} / \mathrm{kg}$ Sal B dose was considered safe.
Behavioral assessment. The Basso, Beattie, and Bresnahan (BBB) locomotor rating scale (14) was used to determine motor function prior to SCI, 24 and 72-h following SCI and then once per week for 7 weeks. Briefly, open-field locomotor activity scores were determined by observing and analyzing behaviors involving all hind limb joint movements, plantar placement, forelimb and hind limb coordination and trunk stability. The BBB scores ranged from 0 (complete paralysis) to 21 (unimpaired locomotion). All behavioral observations were performed at the same time (8:00 p.m.) to avoid variations in the movement of the animals between day and night. All of the rats were evaluated by three trained examiners in a double-blind manner.

Western blot analysis. For euthanasia, SD rats were anesthetized by an intraperitoneal injection of $10 \%$ chloral hydrate $(350 \mathrm{mg} / \mathrm{kg})$. After the rats were fully anaesthetized, rats were sacrificed by decapitation and verification of death was defined by the cessation of breathing. Then, total protein was isolated from the T10 spinal cord tissues or primary spinal cord neurons using a total protein extraction kit (Beijing Solarbio Science \& Technology Co., Ltd.) and was collected following centrifugation at $12,000 \mathrm{x}$ g for $30 \mathrm{~min}$ at $4^{\circ} \mathrm{C}$. A bicinchoninic acid protein assay kit (Pierce; Thermo Fisher Scientific, Inc.) was used to determine the protein concentration. A total of $20 \mu \mathrm{g}$ of protein was loaded per lane and separated using $12 \%$ SDS-PAGE then transferred onto polyvinylidene difluoride membranes and blocked with $5 \%$ fat-free milk at room temperature for 2-h. The membranes were incubated with primary antibodies against Bax (cat. no. ab32503; 1:1,000; Abcam), Bcl-2 (cat. no. ab32124; 1:1,000; Abcam), cleaved-caspase3 (c-caspase3; cat. no. ab2302; 1:1,000; Abcam), total-caspase3 (t-caspase3; cat. no. ab13847; 1:1,000; Abcam), c-caspase9 (cat. no. ab2324; 1:1,000; Abcam), t-caspase9 (cat. no. ab32539; 1:1,000; Abcam,), $\beta$-catenin (cat. no. ab32527; 1:1,000; Abcam), phosphorylated-GSK3 $\beta$ (p-GSK3 $\beta$, cat. no. ab107166; 1:1,000; Abcam), GSK3 $\beta$ (cat. no. ab93926; 1:1,000; Abcam) and anti-GAPDH (cat. no. 2118; 1:5,000; Cell Signaling Technology, Inc.) at $4^{\circ} \mathrm{C}$ overnight. The membranes were subsequently incubated with horseradish peroxidase-conjugated goat anti-rabbit IgG (1:5,000; cat. no. ZB-2301; Beijing Zhongshan Golden Bridge Biotechnology Co.) for $2 \mathrm{~h}$ at room temperature, followed by three washes with Tris-buffered saline and Polysorbate 20. Enhanced chemiluminescence (EMD Millipore; Merck $\mathrm{KGaA}$ ) was used to determine the protein concentrations according to the manufacturer's protocol. The signals were detected using a Super ECL Plus kit (Nanjing KeyGen Biotech Co., Ltd.), and quantitative analysis was performed using UVP software (UVP LLC). Relative protein expression levels were normalized to GAPDH. All experiments were repeated three times. ImageJ 1.43b software (National Institutes of Health) was used for densitometry analysis.

Reverse transcription-quantitative PCR (RT-qPCR) analysis. Total RNA was isolated from spinal cord tissues or primary spinal cord neurons using TRIzol reagent (Life Technologies; Thermo Fisher Scientific, Inc.) according to the manufacturer's protocol. The RNA was reversed-transcribed into cDNA using the TaqMan RNA Reverse Transcription kit (Applied 
A
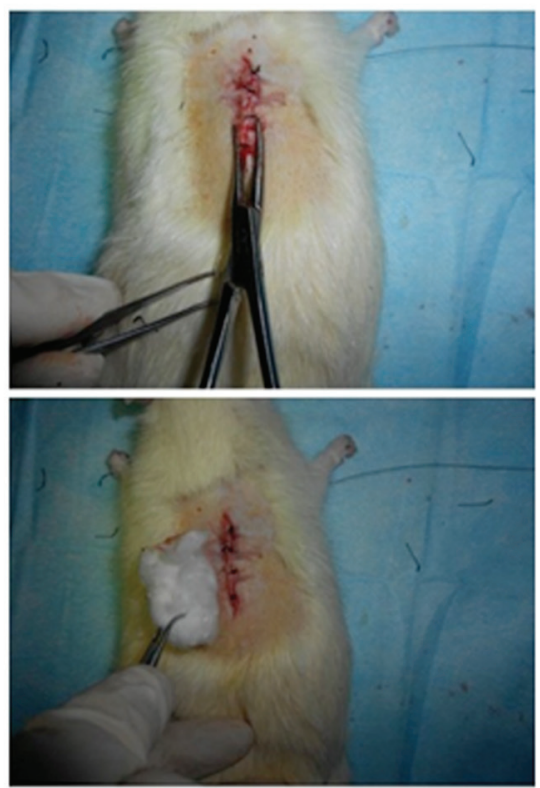

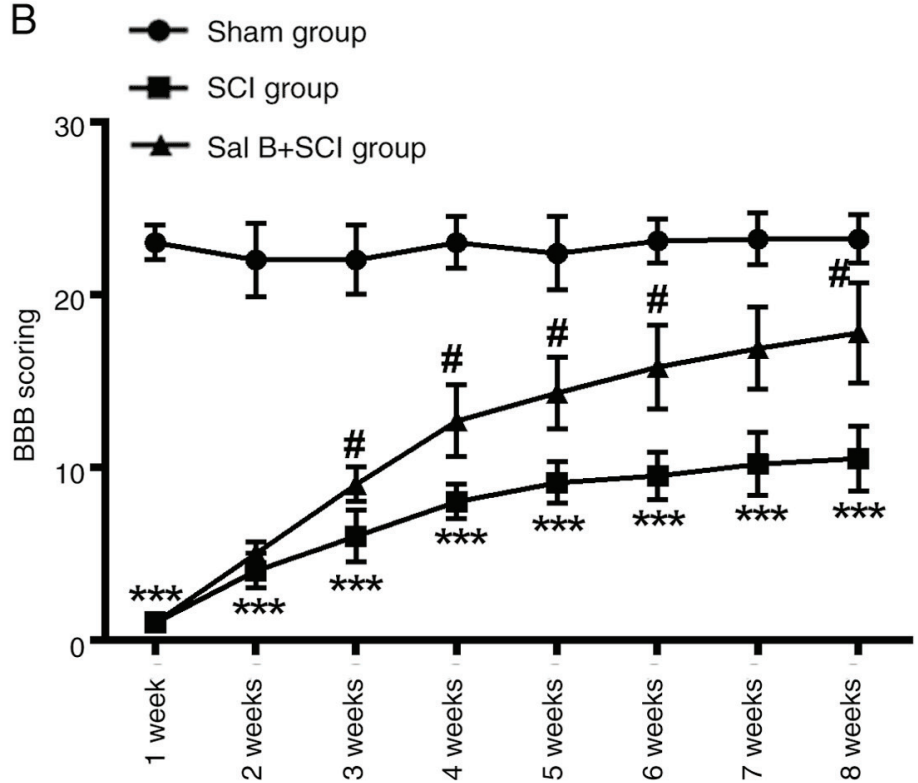

Figure 1. SCI+Sal B group improves locomotor functional recovery following SCI. (A) Representative images of establishment of the SCI rat model. (B) BBB scoring showing that SCI+Sal B group improves locomotor functional recovery following SCI. ${ }^{* * *} \mathrm{P}<0.001$ vs. the sham group; ${ }^{*} \mathrm{P}<0.05$ vs. SCI group. Sal B, salvianolic acid B; SCI, spinal cord injury; BBB, Basso, Beattie, and Bresnahan.

Biosystems; Thermo Fisher Scientific, Inc.). The thermocycling conditions were as follows: Annealing at $65^{\circ} \mathrm{C}$ for $5 \mathrm{sec}$, elongation at $37^{\circ} \mathrm{C}$ for $15 \mathrm{~min}$, inactivation at $85^{\circ} \mathrm{C}$ for $5 \mathrm{sec}$ and then cooled to $4^{\circ} \mathrm{C}$. qPCR was performed using SYBR Green Supermix (Bio-Rad Laboratories, Inc.) and the iCycler iQ Real-Time PCR system (Bio-Rad Laboratories, Inc.) as described previously (16). The thermocycling conditions were as follows: $95^{\circ} \mathrm{C}$ for $10 \mathrm{~min}$ followed by 50 cycles of $95^{\circ} \mathrm{C}$ for $10 \mathrm{sec}, 55^{\circ} \mathrm{C}$ for $10 \mathrm{sec}, 72^{\circ} \mathrm{C}$ for $5 \mathrm{sec}, 99^{\circ} \mathrm{C}$ for $1 \mathrm{sec}, 59^{\circ} \mathrm{C}$ for $15 \mathrm{sec}, 95^{\circ} \mathrm{C}$ for $1 \mathrm{sec}$ and then cooled to $40^{\circ} \mathrm{C}$. Relative mRNA expression was normalized to the endogenous control, GAPDH, using the $2^{-\Delta \Delta \mathrm{Cq}}$ method (17).

The primers used are as follows: Lymphoid enhancer binding factor 1 (LEF-1; forward primer 5'-TACGCTAAA GGAGAGCGCAG-3' and reverse primer 5'-GCTGTCATT CTGGGACCTGT-3'; GenBank accession no: NM 130429.1); HNF1 homeobox A (TCF-1; forward primer 5'-GAGCTGCCA ACCAAAAAGGG-3' and reverse primer 5'-CCAGTTGTA GACACGCACCT-3'; GenBank accession no: NM 012669.1); and GAPDH (forward primer 5'-CATGAGAAGTATGAC AACAGCCT-3' and reverse primer 5'-AGTCCTTCCACG ATACCAAAGT-3').

Terminal deoxynucleotidyl-transferase-mediated dUTP nick end labeling (TUNEL). In the SCI model group, apoptotic cells in the spinal cord were examined 7 days following SCI, while the number of apoptotic cells in the Sal B group was evaluated 7 days post-administration of Sal B. Spinal cord tissue sections (4 $\mu \mathrm{m}$ thickness) were acquired following fixation using $10 \%$ paraformaldehyde (Beijing Solarbio Science \& Technology Co., Ltd.), dehydration using an alcohol series (xylene for $3 \mathrm{~min}$; absolute ethanol for $3 \mathrm{~min}$; $95 \%$ ethanol for $3 \mathrm{~min}$; and $85 \%$ ethanol for $3 \mathrm{~min}$ ), paraffin-embedding and serial sectioning. Nuclear fragmentation was detected using TUNEL staining with an In Situ Cell Death Detection kit (cat. no. 12156792910, Roche
Diagnostics), according to the supplier's instructions. Briefly, the tissues were fixed with $4 \%$ paraformaldehyde for $30 \mathrm{~min}$ at room temperature, followed by incubation with TUNEL buffer for $1 \mathrm{~h}$ at $37^{\circ} \mathrm{C}$. Following rinsing with PBS, the slides were sealed with Glycerol Gelatin aqueous slide mounting medium (cat. no. S2150-10 ml, Beijing Solarbio Science \& Technology Co., Ltd.). Then, the number of TUNEL-positive apoptotic cells and the total number of cells in five different random high-power fields were counted using a fluorescence microscope (Olympus Corporation) at a magnification of $\mathrm{x} 400$. The nucleus was stained with $0.5 \mu \mathrm{g} / \mathrm{ml}$ DAPI at room temperature for $10 \mathrm{~min}$ for observing the total number of cells and the apoptotic cells were stained with TUNEL. The percentage of apoptotic cells was calculated as the ratio of the number of TUNEL-positive cells to the total number of cells.

Immunofluorescence staining. The tissue samples were washed three times in PBS for $5 \mathrm{~min}$. Following three washes with PBS for $5 \mathrm{~min}$, the slides were blocked with $8 \%$ bovine serum albumin (BSA; Sigma-Aldrich; Merck KGaA) at room temperature for $2 \mathrm{~h}$. The coverslips were incubated with an antibody against neuronal nuclei (1:80; cat. no. ab177487; NeuN; neuronal marker; Abcam) or $\beta$-catenin (1:80; cat. no. ab32572; Abcam) in a humidified chamber overnight at $4^{\circ} \mathrm{C}$. Then, the slides were washed with PBS three times and incubated with tetramethylrhodamine-conjugated anti-rabbit immunoglobulin G (1:500; cat. no. ZDR5209; Zhongshan Gold Bridge Biotechnology Co., Ltd.) and with DAPI (1:1,000; cat. no. C0060; Solarbio Science \& Technology Co., Ltd.) for $20 \mathrm{~min}$ at room temperature. Following incubation with a secondary antibody, the slides were washed three times with PBS in the dark, and coverslips were mounted with mounting medium on coated glass slides. The slides were sealed at room temperature for $\sim 1 \mathrm{~h}$ in the dark then the fluorescence intensity was examined using a fluorescence microscope (magnification, $\mathrm{x} 40$ ). 
A
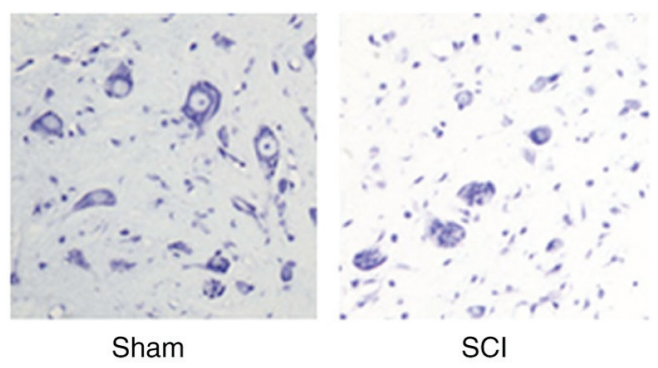

$\mathrm{SCl}$

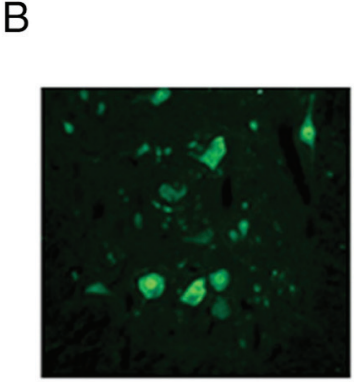

Sham

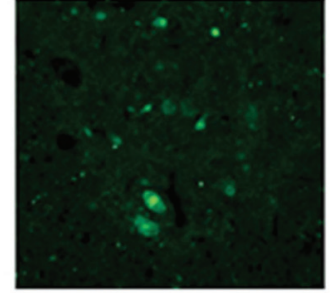

$\mathrm{SCl}$

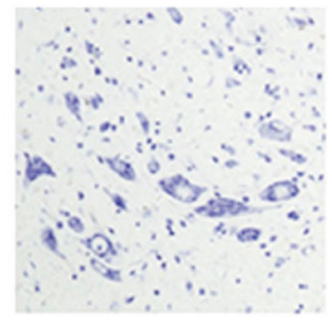

Sal B+SCl

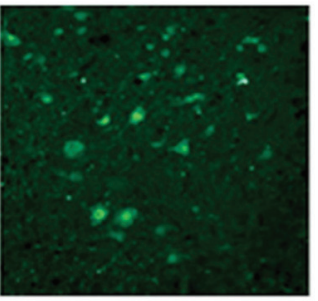

Sal B+SCl
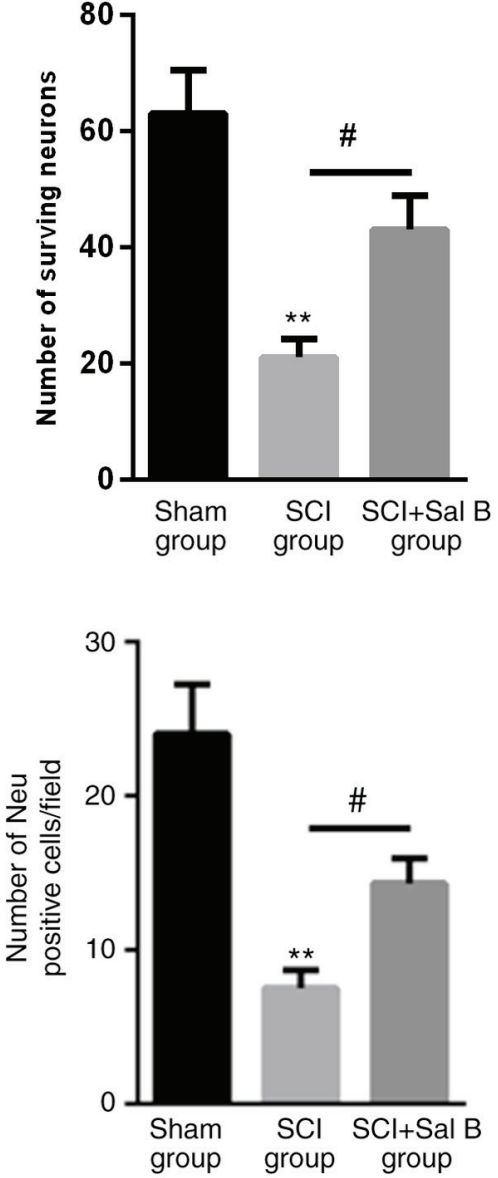

Figure 2. Sal B enhances motor neuron survival following SCI. (A) Nissl staining (blue) demonstrated that the number of motor neurons in the anterior horn was significantly increased in the Sal B group. Magnification, x40. (B) Compared with SCI, SCI+Sal B group was found to increase the number of NeuN-positive cells (green staining) in the spinal cord. Magnification, $\mathrm{x} 40{ }^{*}{ }^{* *} \mathrm{P}<0.01$ vs. the sham group; ${ }^{\#} \mathrm{P}<0.05$ vs. the $\mathrm{SCI}$ group. Sal $\mathrm{B}$, salvianolic acid $\mathrm{B}$; SCI, spinal cord injury; NeuN, neuronal nuclei.

Nissl staining. Spinal cord tissue sections (4 $\mu \mathrm{m}$ thickness) were stained with Nissl staining solution (cat. no. C0117; Beyotime Institute of Biotechnology) at $37^{\circ} \mathrm{C}$ for $5 \mathrm{~min}$. The slides were then washed with $\mathrm{ddH}_{2} \mathrm{O}$ for twice for $5 \mathrm{sec}$. Subsequently, the slides were rinsed with $95 \%$ ethanol and then twice with $70 \%$ ethanol, following which mounting medium (cat. no. ZLI-9552; Zhongshan Gold Bridge Biotechnology Co., Ltd.) was added. Slides were observed using a fluorescence microscope (magnification, $x 40$ ), where five separate fields of view were taken per slide. DAPI staining was used to quantify the total number of cells per field of view.

Statistical analysis. The data were analyzed using SPSS software (version 13.0; SPSS, Inc.). The data are expressed as the mean \pm standard error of the mean. The results were analyzed using Student's t-test or one-way analysis of variance followed by Tukey's honest significant difference test. $\mathrm{P}<0.05$ was considered to indicate a statistically significant difference.

\section{Results}

Sal B treatment improves locomotor functional recovery following SCI. The SCI rat model was successfully established
(Fig. 1A). To evaluate the protective role of Sal B on locomotor functional recovery following SCI, BBB scores were determined. It was determined that the hindquarters of the rats in the Sal B group and SCI+Sal B group were paralyzed following SCI compared with that of the sham group (Fig. 1B). Locomotion gradually improved between one and two weeks following SCI. More importantly, Sal B treatment significantly increased locomotor functional recovery in SCI rats compared with PBS-treated SCI rats between three and eight weeks following SCI (Fig. 1B).

Sal B enhances motor neuron survival following SCI. To evaluate the effect of Sal B on motor neuron survival, Nissl staining was carried out to evaluate the number of motor neurons in the spinal cord anterior horn as well as the tissue lesion in the spinal cord 14 days following SCI (Fig. 2A). In contrast to that of sham group, the number of surviving neurons were significantly decreased compared with that of SCI and SCI+Sal B group (Fig. 2A). Compared with the $\mathrm{SCI}$ group, the number of motor neurons in the anterior horn was significantly increased in the Sal B group (Fig. 2A). In addition, compared with the SCI group, Sal B was found to significantly increase the number of NeuN-positive cells in the spinal cord (Fig. 2B). 

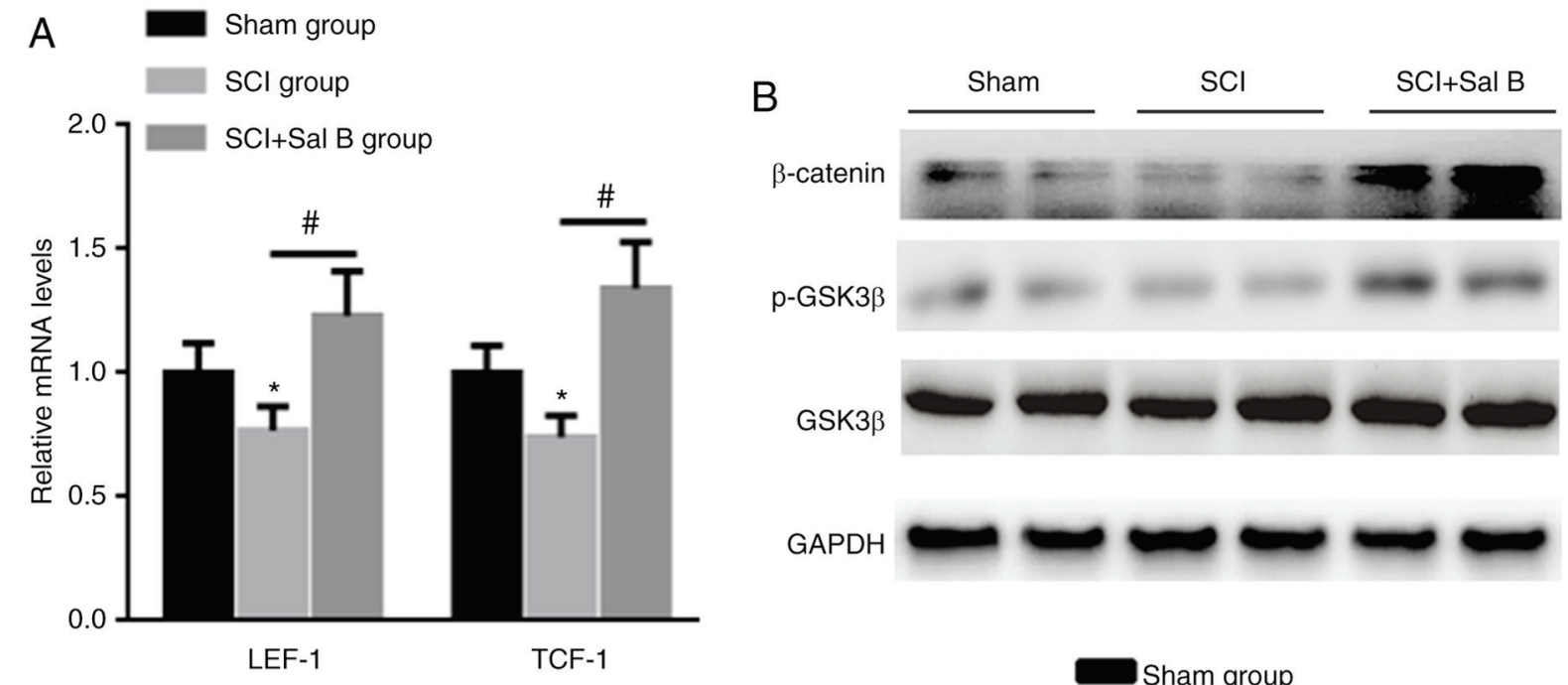

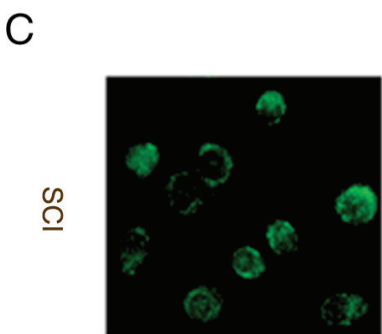

FITC

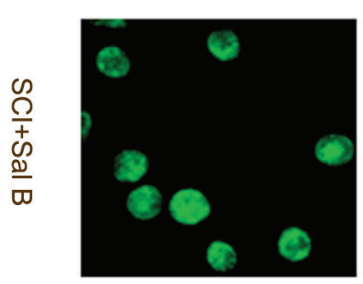

FITC

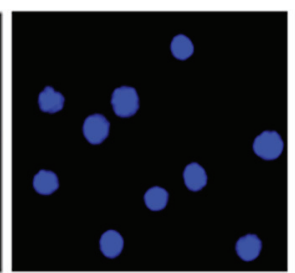

Hoechst

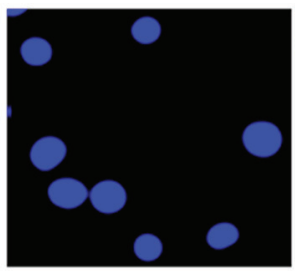

Hoechst

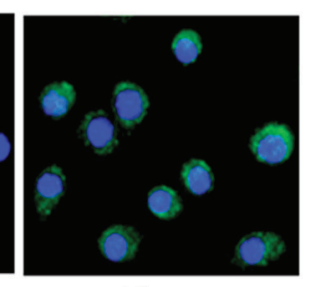

Merge

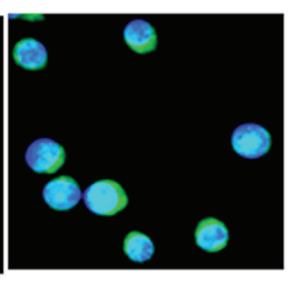

Merge

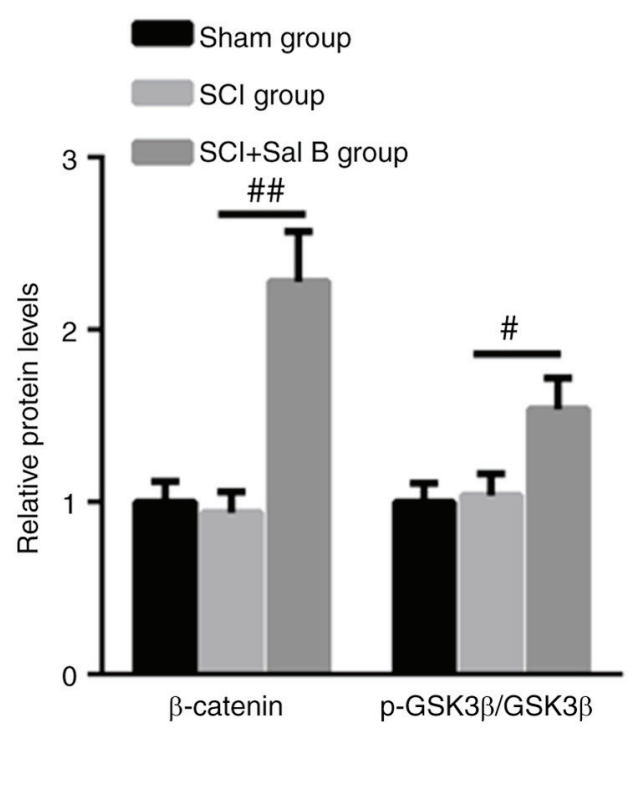

Figure 3. Sal B enhances the activation of the Wnt/ $\beta$-catenin signaling pathway following SCI. (A) Reverse transcription-quantitative PCR analysis determined that SCI+Sal B group significantly enhanced the mRNA levels of LEF-1 and TCF-1. (B) Western blot analysis showed that SCI+Sal B group increased the phosphorylation of GSK3 $\beta$ and the expression of $\beta$-catenin. (C) Immunofluorescence analysis showed the translocation of $\beta$-catenin from cytoplasm to nucleus in the spinal cord tissues of rats in SCI+Sal B group compared with the SCI group 2 weeks after SCI induction. Green represents $\beta$-catenin staining, blue represents nuclear staining. Magnification, $\mathrm{x} 40 .{ }^{*} \mathrm{P}<0.001$ vs. the sham group; ${ }^{*} \mathrm{P}<0.05$ and ${ }^{\# \#} \mathrm{P}<0.01$ vs. the SCI group. Sal B, salvianolic acid B; SCI, spinal cord injury; p, phosphorylated; GSK3 $\beta$ LEF-1; TCF-1.

Sal B enhances the activation of the Wnt/ $\beta$-catenin signaling pathway following SCI. Next, investigation into whether Sal $\mathrm{B}$ can activate the $\mathrm{Wnt} / \beta$-catenin signaling pathway in spinal cord tissues following SCI was performed. RT-qPCR analysis showed that Sal B treatment significantly enhanced the mRNA levels of LEF-1 and TCF-1 (Fig. 3A) compared to the SCI group. Furthermore, phosphorylation of GSK $3 \beta$ at Ser9 was assessed, which indicates a state of inactivation. The data demonstrated that the phosphorylation of GSK $3 \beta$ was significantly increased in the spinal cord tissues of rats treated with Sal B rats 2 weeks following SCI compared to the SCI group (Fig. 3B). Moreover, Sal B treatment enhanced the expression of $\beta$-catenin compared to SCI group (Fig. 3B). In addition, $\beta$-catenin translocated from the cytoplasm into the nucleus in the spinal cord tissues of rats treated with Sal B 2 weeks following SCI compared with the SCI group, suggesting that
Wnt/ $\beta$-catenin signaling was activated (Fig. 3C). These results suggested that $\mathrm{Sal}$ B treatment can activate Wnt/ $\beta$-catenin signaling following SCI.

Sal B decreases neuronal apoptosis following SCI. Finally, whether Sal B inhibits neuronal apoptosis in SCI rats was explored. Western blot analysis determined that Sal B treatment significantly decreased the expression of pro-apoptosis proteins, including Bax, cleaved caspase-3/total-caspase-3 and cleaved caspase-9/total caspase-9, in spinal cord tissues following SCI but enhanced the expression of $\mathrm{Bcl}-2$, an anti-apoptotic protein (Fig. 4A). Furthermore, TUNEL staining demonstrated that, compared with vehicle treatment, Sal B treatment decreased the number of TUNEL-positive neurons (Fig. 4B). These observations indicated that Sal B suppressed neuronal apoptosis in SCI rats. 
A

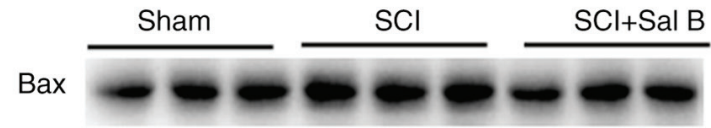

t-caspase-3

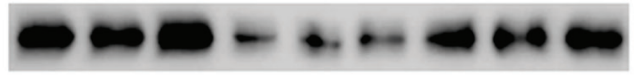

c-caspase-3

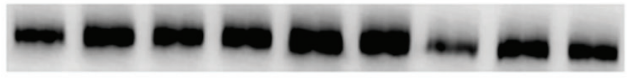

t-caspase-9

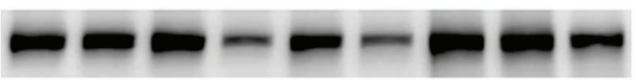

c-caspase- 9

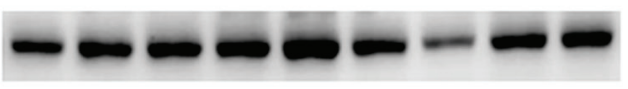

$\mathrm{Bcl}-2$

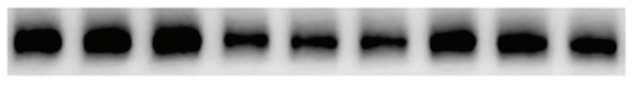

GAPDH

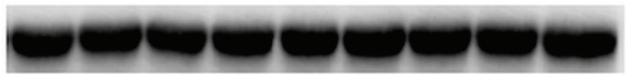

B
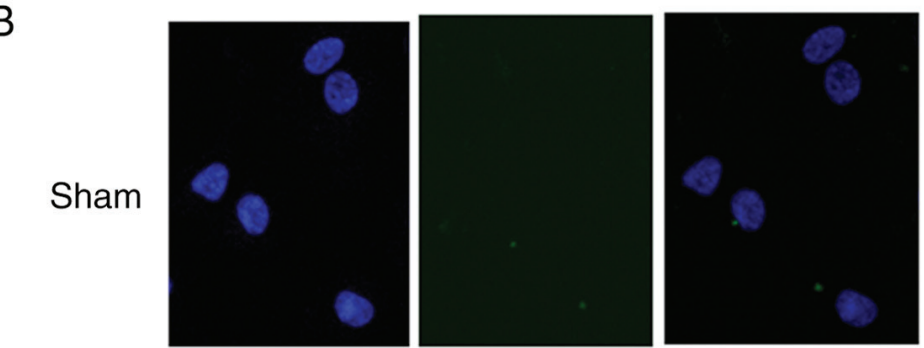

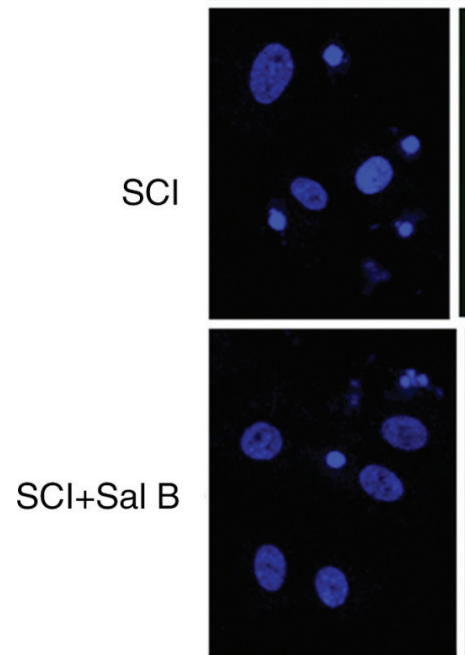

DAPI
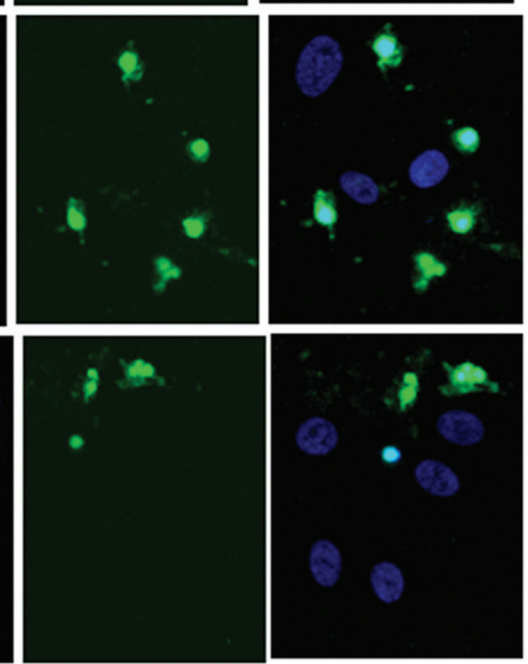

TUNEL
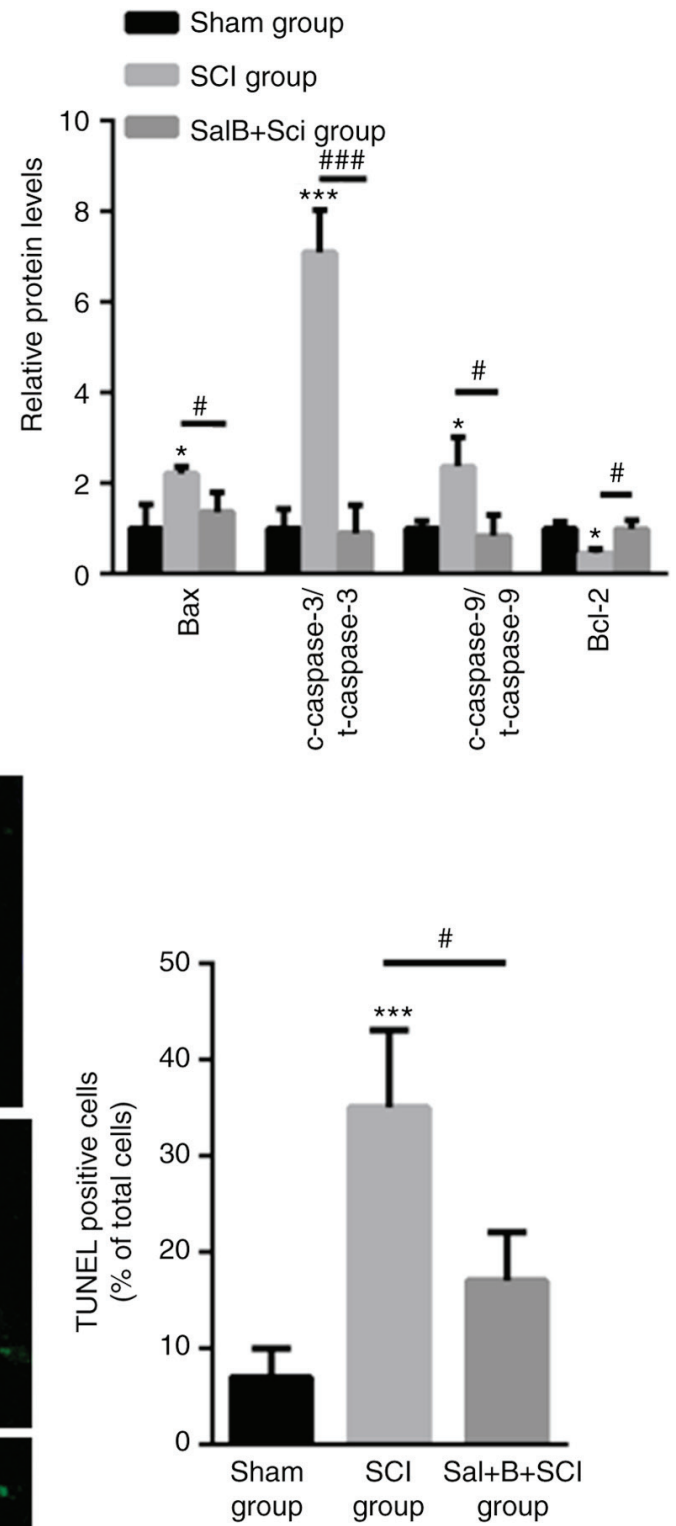

Figure 4. Sal B decreases neuronal apoptosis following SCI. (A) Western blot analysis showed that SCI+Sal B group significantly decreased the expression of Bax, c-caspase-3 and c-caspase-9 in spinal cord tissues following SCI but enhanced the expression of Bcl-2. (B) TUNEL staining demonstrated that, compared with SCI group, SCI+Sal B group decreased the number of TUNEL-positive neuron cells. Magnification, $\mathrm{x} 40$. $^{*} \mathrm{P}<0.05$ and ${ }^{* * *} \mathrm{P}<0.001 \mathrm{vs}$. the sham group; ${ }^{\#} \mathrm{P}<0.05$ and ${ }^{\# \# \#} \mathrm{P}<0.001$ vs. the SCI group. Sal B, salvianolic acid B; SCI, spinal cord injury; TUNEL, terminal deoxynucleotidyl-transferase-mediated dUTP nick end labeling; c, cleaved; t, total.

\section{Discussion}

In the present study, it was demonstrated that Sal B enhanced the phosphorylation of GSK3 $\beta$ and the expression of $\beta$-catenin in spinal cord neurons following SCI. Moreover, the number of motor neurons and functional recovery was increased following Sal B treatment, whilst the spinal cord lesion size was reduced in SCI rats. In addition, Sal B suppressed neuronal apoptosis following SCI. Taken together, these observations indicated that the mechanism of Sal B neuroprotective effects of Sal B may be via activation of the $\mathrm{Wnt} / \beta$-catenin signaling pathway.

In vivo studies have demonstrated that $\mathrm{Sal} \mathrm{B}$ is protective against cerebral ischemia and reperfusion, and SCI $(18,19)$. Sal B protects rats from SCI via reducing the inflammatory 
reaction and increasing blood supply to damaged tissues (10). However, the specific mechanism underlying the effect of Sal $\mathrm{B}$ on SCI remains unclear.

The present data demonstrated that Sal B increased the number of motor neurons in the spinal cord anterior horn. Meanwhile, the lesion size was reduced by Sal B treatment in SCI rats. BBB scoring also determined that Sal B treatment increased locomotor function following SCI. These findings were consistent with the literature where the neuroprotective role of Sal B following SCI was identified $(11,13)$.

Previous studies have indicated that activation of the Wnt/ $\beta$-catenin signaling pathway serves a key role in functional recovery and axonal regeneration following SCI $(20,21)$. It has been demonstrated that $\mathrm{Wnt} / \beta$-catenin signaling activation enhances neuronal survival, axonal guidance and neuropathic pain remission $(1,22)$. Therefore, determining how to properly modulate the $\mathrm{Wnt} / \beta$-catenin signaling pathway may shed light on SCI treatment (23). In brief, $\beta$-catenin receives a signal from membrane receptors then is transmitted to the nucleus, where $\beta$-catenin binds LEF/TCF transcription factors, thereby activating target genes (24). In addition, $\beta$-catenin enhances the regeneration of axons, suppresses apoptosis and improves functional recovery following SCI (25). Thus, it has been suggested that the $\mathrm{Wnt} / \beta$-catenin signaling pathway may be a major contributor to neuroprotection following SCI (22). Here, the expression of $\beta$-catenin was significantly increased by Sal $\mathrm{B}$ treatment and was accompanied by the increased transcription of LEF-1 and TCF-1. These findings suggested that the Wnt/ $\beta$-catenin signaling pathway is activated by Sal B and indicated that it may be the mechanism underlying the action of Sal B following its clinical application.

In addition, the effect of Sal B on neural cell apoptosis was evaluated. Induction of cell apoptosis, which enhances the loss of neurons and reduces neuronal functional recovery, has been widely reported following SCI $(26,27)$. In the present study, western blot analysis determined that the expression levels of Bax, cleaved caspase- 3 and cleaved caspase- 9 were increased in spinal cord tissues following SCI but the expression of Bcl-2 decreased. By contrast, Sal B treatment reversed this effect. Treatment with Sal B also decreased neuronal apoptosis following SCI. These results demonstrated that the effect of Sal B on neuronal apoptosis following SCI is partially mediated by the $\mathrm{Wnt} / \beta$-catenin signaling pathway.

Taken together, the present findings demonstrated that Sal B was effective in the treatment of SCI and improved the neurological function of rats therefore, is worthy of further investigation. However, Sal B is characterized by multi-pathway and multi-target pharmacological activity. Therefore, whether Sal B has side effects on other organs such as cardiovascular, cerebrovascular, liver and kidney, should be further explored and may limit its application for SCI treatment. Further studies are necessary to explore the various effects of Sal B on the Wnt signaling pathway at different times following SCI in rats. In addition, it is useful to explore the in-depth molecular mechanism via both in vitro and in vivo experiments to support the clinical application of Sal B.

In summary, the present study provided novel data demonstrating the neuroprotective effect of Sal B following SCI and determined that the underlying mechanism likely involved via the Wnt/ $\beta$-catenin signaling pathway. The present findings may shed finding on the clinical application of Sal B for future SCI treatment.

\section{Acknowledgements}

Not applicable.

\section{Funding}

The present study was supported by a grant from the Shandong Provincial Hospital Affiliated with Shandong University (grant no. SDPH-20160912).

\section{Availability of data and materials}

The datasets used and/or analyzed during the current study are available from the corresponding author on reasonable request.

\section{Authors' contributions}

HZ performed the experiments and analyzed the data. YL and LS performed the animal experiments. MF performed part of the animal experiments. YZ designed the experiments, analyzed the data and gave final approval of the version to be published. All authors read and approved the final manuscript.

\section{Ethics approval and consent to participate}

The present study was approved by the Animal Ethics Committee at Shandong Provincial Hospital Affiliated with Shandong University (Shandong, China).

\section{Patient consent for publication}

Not applicable.

\section{Competing interests}

The authors declare that they have no competing interests.

\section{References}

1. Shen Z, Zhou Z, Gao S, Guo Y, Gao K, Wang H and Dang X: Melatonin inhibits neural cell apoptosis and promotes locomotor recovery via activation of the $\mathrm{Wnt} / \beta$-catenin signaling pathway after spinal cord injury. Neurochem Res 42: 2336-2343, 2017.

2. Xu K, Chen QX, Li FC, Chen WS, Lin M and Wu QH: Spinal cord decompression reduces rat neural cell apoptosis secondary to spinal cord injury. J Zhejiang Univ Sci B 10: 180-187, 2009.

3. Zhou Z, Chen S, Zhao H, Wang C, Gao K, Guo Y, Shen Z, Wang Y, Wang H and Mei X: Probucol inhibits neural cell apoptosis via inhibition of mTOR signaling pathway after spinal cord injury. Neuroscience 329: 193-200, 2016.

4. Gao K, Shen Z, Yuan Y, Han D, Song C, Guo Y and Mei X: Simvastatin inhibits neural cell apoptosis and promotes locomotor recovery via activation of $\mathrm{Wnt} / \beta$-catenin signaling pathway after spinal cord injury. J Neurochem 138: 139-149, 2016.

5. Yamagami T, Pleasure DE, Lam KS and Zhou CJ: Transient activation of $\mathrm{Wnt} / \beta$-catenin signaling reporter in fibrotic scar formation after compression spinal cord injury in adult mice. Biochem Biophys Res Commun 496: 1302-1307, 2018.

6. Herman PE, Papatheodorou A, Bryant SA, Waterbury CKM, Herdy JR, Arcese AA, Buxbaum JD, Smith JJ, Morgan JR and Bloom O: Highly conserved molecular pathways, including Wnt signaling, promote functional recovery from spinal cord injury in lampreys. Sci Rep 8: 742, 2018 
7. Hsu HC, Liu YS, Tseng KC, Tan BC, Chen SJ and Chen HC: LGR5 regulates survival through mitochondria-mediated apoptosis and by targeting the $\mathrm{Wnt} / \beta$-catenin signaling pathway in colorectal cancer cells. Cell Signal 26: 2333-2342, 2014.

8. LiB,Zeng M,He W,Huang X, Luo L,Zhang H and Deng DY: Ghrelin protects alveolar macrophages against lipopolysaccharide-induced apoptosis through growth hormone secretagogue receptor 1a-dependent c-Jun N-terminal kinase and Wnt/beta-catenin signaling and suppresses lung inflammation. Endocrinology 156: 203-217, 2015.

9. Libro R, Giacoppo S, Bramanti P and Mazzon E: Is the Wnt/ $\beta$-catenin pathway involved in the anti-inflammatory activity of glucocorticoids in spinal cord injury? Neuroreport 27: 1086-1094, 2016.

10. Fu J, Fan HB, Guo Z, Wang Z, Li XD, Li J and Pei GX: Salvianolic acid $B$ attenuates spinal cord ischemia-reperfusion-induced neuronal injury and oxidative stress by activating the extracellular signal-regulated kinase pathway in rats. J Surg Res 188: 222-230, 2014

11. Fan ZK, Lv G, Wang YF, Li G, Yu DS, Wang YS, Zhang YQ, Mei XF and Cao Y: The protective effect of salvianolic acid $B$ on blood-spinal cord barrier after compression spinal cord injury in rats. J Mol Neurosci 51: 986-993, 2013.

12. Zhu Z, Ding L, Qiu WF, Wu HF and Li R: Salvianolic acid B protects the myelin sheath around injured spinal cord axons. Neural Regen Res 11: 487-492, 2016.

13. Bi XB, Deng YB, Gan DH and Wang YZ: Salvianolic acid B promotes survival of transplanted mesenchymal stem cells in spinal cord-injured rats. Acta Pharmacol Sin 29: 169-176, 2008.

14. Chen H, Li J, Liang S, Lin B, Peng Q, Zhao P, Cui J and Rao Y: Effect of hypoxia-inducible factor-1/vascular endothelial growth factor signaling pathway on spinal cord injury in rats. Exp Ther Med 13: 861-866, 2017.

15. Vachon P, Faubert S, Blais D, Comtois A and Bienvenu JG: A pathophysiological study of abdominal organs following intraperitoneal injections of chloral hydrate in rats: Comparison between two anaesthesia protocols. Lab Anim 34: 84-90, 2000.

16. Guo J, Li M, Meng X, Sui J, Dou L, Tang W, Huang X, Man Y, Wang S and Li J: MiR-291b-3p induces apoptosis in liver cell line NCTC1469 by reducing the level of RNA-binding protein HuR. Cell Physiol Biochem 33: 810-822, 2014.

17. Livak KJ and Schmittgen TD: Analysis of relative gene expression data using real-time quantitative PCR and the 2(-Delta Delta C(T)) method. Methods 25: 402-408, 2001.

18. Li S and Wang J: Salvianolic acid B prevents steroid-induced osteonecrosis of the femoral head via PPARg expression in rats. Exp Ther Med 13: 651-656, 2017.
19. Lou Y, Wang C, Zheng W, Tang Q, Chen Y, Zhang X, Guo X and Wang J: Salvianolic acid B inhibits IL-1 $\beta$-induced inflammatory cytokine production in human osteoarthritis chondrocytes and has a protective effect in a mouse osteoarthritis model. Int Immunopharmacol 46: 31-37, 2017.

20. Lu GB, Niu FW, Zhang YC, Du L, Liang ZY, Gao Y, Yan TZ, Nie ZK and Gao K: Methylprednisolone promotes recovery of neurological function after spinal cord injury: Association with $\mathrm{Wnt} / \beta$-catenin signaling pathway activation. Neural Regen Res 11: 1816-1823, 2016.

21. Miyashita T, Koda M, Kitajo K, Yamazaki M, Takahashi K, Kikuchi A and Yamashita T: Wnt-Ryk signaling mediates axon grow th inhibition and limits functional recovery after spinal cord injury. J Neurotrauma 26: 955-964, 2009.

22. Strand NS, Hoi KK, Phan TMT, Ray CA, Berndt JD and Moon RT: Wnt/ $\beta$-catenin signaling promotes regeneration after adult zebrafish spinal cord injury. Biochem Biophys Res Commun 477: 952-956, 2016.

23. Briona LK, Poulain FE, Mosimann C and Dorsky RI: Wnt $/ \beta$-catenin signaling is required for radial glial neurogenesis following spinal cord injury. Dev Biol 403: 15-21, 2015.

24. Gifre L, Vidal J, Carrasco JL, Filella X, Ruiz-Gaspà S, Muxi A, Portell E, Monegal A, Guañabens N and Peris P: Effect of recent spinal cord injury on wnt signaling antagonists (sclerostin and dkk-1) and their relationship with bone loss. A 12-month prospective study. J Bone Miner Res 30: 1014-1021, 2015.

25. Jiang SD, Yan J, Jiang LS and Dai LY: Down-regulation of the Wnt, estrogen receptor, insulin-like growth factor-I, and bone morphogenetic protein pathways in osteoblasts from rats with chronic spinal cord injury. Joint Bone Spine 78: 488-492, 2011.

26. Fu H, Li F, Thomas S and Yang Z: Hyperbaric oxygenation alleviates chronic constriction injury (CCI)-induced neuropathic pain and inhibits GABAergic neuron apoptosis in the spinal cord. Scand J Pain 17: 330-338, 2017.

27. Wang XJ, Kong KM, Qi WL, Ye WL and Song PS: Interleukin-1 beta induction of neuron apoptosis depends on p38 mitogen-activated protein kinase activity after spinal cord injury. Acta Pharmacol Sin 26: 934-942, 2005.

(i) $($ ) This work is licensed under a Creative Commons cc) Attribution-NonCommercial-NoDerivatives 4.0 International (CC BY-NC-ND 4.0) License. 